\title{
Erratum zu: Monika Jäckle, Bettina Wuttig und Christian Fuchs (Hrsg.) (2017)
}

Handbuch Trauma - Pädagogik - Schule

\section{Erratum zu:}

Sozial Extra 2019

https://doi.org/10.1007/s12054-019-00244-8

Eine der Herausgeber_innen des rezensierten Handbuchs war fälschlicherweise mit ,Monika Jäggle‘ angegeben. Richtig ist ,Monika Jäckle‘. Außerdem hieß es an einer Stelle fälschlich „Anna Gregor“ statt „Anja Gregor".

Beides wurde im Original korrigiert.

Angenommen. 9. November 2021

Die Online-Version des Originalartikels ist unter https:// doi.org/10.1007/s12054-019-00244-8 zu finden. 